\title{
Large Right Ventricular Thrombus
}

\author{
Trombo Volumoso do Ventrículo Direito
}

\author{
Carla SOUSA ${ }^{1}$, Pedro ALMEIDA , Alexandra GONÇALVES ${ }^{1}$, João RODRIGUES ${ }^{1}$, Inês RANGEL ${ }^{1}$, Filipe MACEDO ${ }^{1}$, M. $^{2}$. \\ Júlia MACIEL ${ }^{1}$ \\ Acta Med Port 2014 May-Jun;27(3):390-393
}

\section{ABSTRACT}

Right ventricular thrombosis is a rare yet potentially fatal condition. It has been described in association with hypercoagulability states, autoimmune diseases and dilated cardiomyopathy. Echocardiography constitutes the election tool for diagnosis and characterization of these entities, allowing for the differentiation between the various types of thrombi. We present a case of a patient with alcoholic dilated cardiomyopathy admitted for congestive heart failure and lower respiratory infection. In the diagnostic approach, a routine echocardiography revealed a large mural right ventricular thrombus in association with severe biventricular dysfunction. The patient was proposed for anticoagulation strategy, which he refused.

Keywords: Cardiomyopathy, Alcoholic; Embolism; Coronary Thrombosis; Echocardiography; Ventricular Dysfunction, Right.

\section{RESUMO}

A formação de trombos no ventrículo direito corresponde a uma situação rara porém potencialmente fatal. Tem sido descrita em associação a estados de hipercoagulabilidade, doenças autoimunes e cardiopatia dilatada. A ecocardiografia constitui o método de eleição para o diagnóstico e caracterização destas estruturas, permitindo, inclusive, a diferenciação entre os diversos tipos de trombos possíveis. Apresentamos o caso de um doente com miocardiopatia dilatada de etiologia alcoólica que foi admitido por insuficiência cardíaca congestiva e infeção respiratória baixa. Durante a marcha diagnóstica, o ecocardiograma de rotina revelou a presença de um volumoso trombo mural no ventrículo direito, em associação a disfunção sistólica biventricular de grau severo. Foi proposto o início de hipocoagulação oral, estratégia que o doente recusou.

Palavras-chave: Cardiomiopatia Alcoólica; Trombose Coronária; Ecocardiografia; Disfunção; Ventricular Direita.

\section{INTRODUCTION}

Intracardiac thrombus may develop as a consequence of multiple underlying cardiac disorders affecting valves and myocardium. ${ }^{1}$ Thrombi located in either right or left sides of the heart are dangerous situations as they might give rise to pulmonary or systemic emboli, respectively. ${ }^{1}$

Right ventricular thrombi are extremely rare, especially when not associated with thrombus in the left ventricle. They have been described in the setting of autoimmune diseases (such as Beçhet disease), hypercoagulability states, right ventricular pacing and right ventricular infarction, amongst others. ${ }^{2,3}$ The amplified use of two-dimensional echocardiography has led to increased detection of these thrombi, particularly in patients with suspected or confirmed pulmonary emboli, but also in patients with congestive heart failure.

\section{CASE REPORT}

A 59 year old man with history of alcoholic dilated cardiomyopathy and severe left ventricular dysfunction was admitted to our center for congestive heart failure. He was a heavy drinker (over $200 \mathrm{~g}$ of alcohol per day during 40 years) and smoker ( 80 packs year).

$\mathrm{He}$ had been previously followed in a heart failure clinic, but he eventually abandoned consults as well as pharmacologic treatment.
At the current admission, he presented with resting dyspnea, worsening orthopnea, cough and purulent sputum. He was hypotensive (blood pressure was 88/ $55 \mathrm{mmHg}$ ), heart rate was 64 beats per minute and peripheral oxygen saturation was normal $(100 \%)$. His heart auscultation revealed a grade III/VI holosystolic murmur and he had bilateral crackles in the lower lung half. There was evidence of bilateral pitting edema till the knees. The electrocardiogram showed sinus rhythm and complete right bundle branch block. The chest X-ray showed clear signs of fluid overload. The blood work revealed microcytic hypochromic anemia (hemoglobin 8.6 $\mathrm{g} / \mathrm{dL}$ ) and elevated brain natriuretic peptide $(7334 \mathrm{pg} / \mathrm{mL})$. Transthoracic echocardiography revealed severe dilatation of all heart chambers, severe left ventricular dysfunction (ejection fraction estimated by the Simpson method was $10 \%$ ) associated with severely depressed right ventricular function (tricuspid annular plane systolic excursion $10 \mathrm{~mm}$ ) (Fig. 1 and Video 1). Severe functional mitral and tricuspid regurgitations were evident (Fig. 1 and Videos 2 and $3)$. In the apex of the right ventricle, there was an image suggestive of a thrombus. A high frequency probe allowed for a better characterization of this thrombus, which was found to be large, non mobile and multilobed (maximum dimensions of $24 \times 11 \mathrm{~mm}$ ) (Fig. 2).

1. Cardiology Department. Centro Hospitalar S. João. Porto. Portugal.

Recebido: 01 de Agosto de 2013 - Aceite: 08 de Setembro de 2013 | Copyright $\odot$ Ordem dos Médicos 2014 


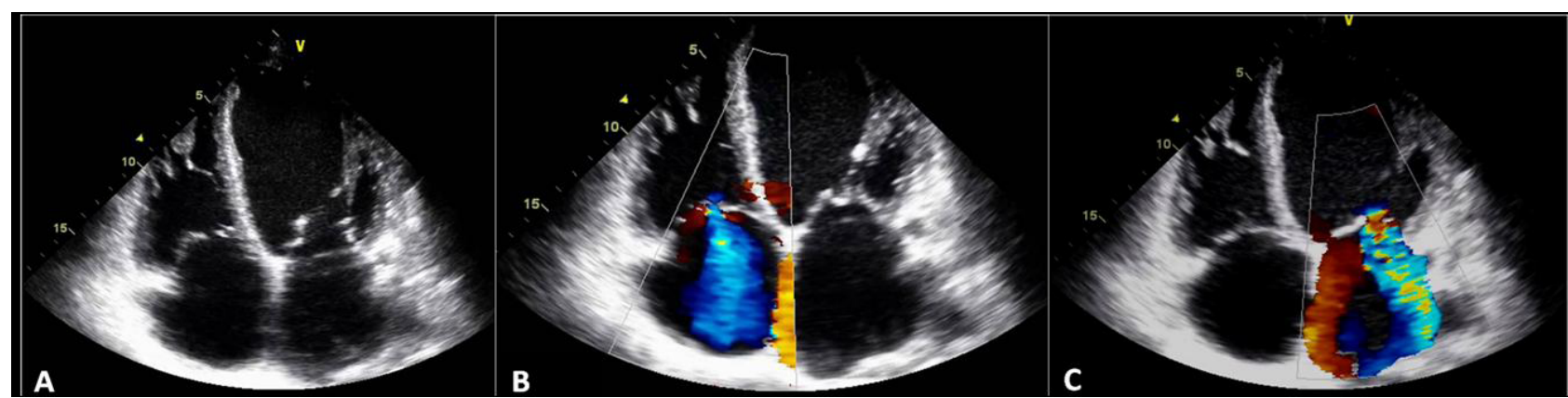

Figure 1 - Apical four chamber views documenting severe chamber dilatation $(A)$, severe tricuspid $(B)$ and mitral regurgitation (C)

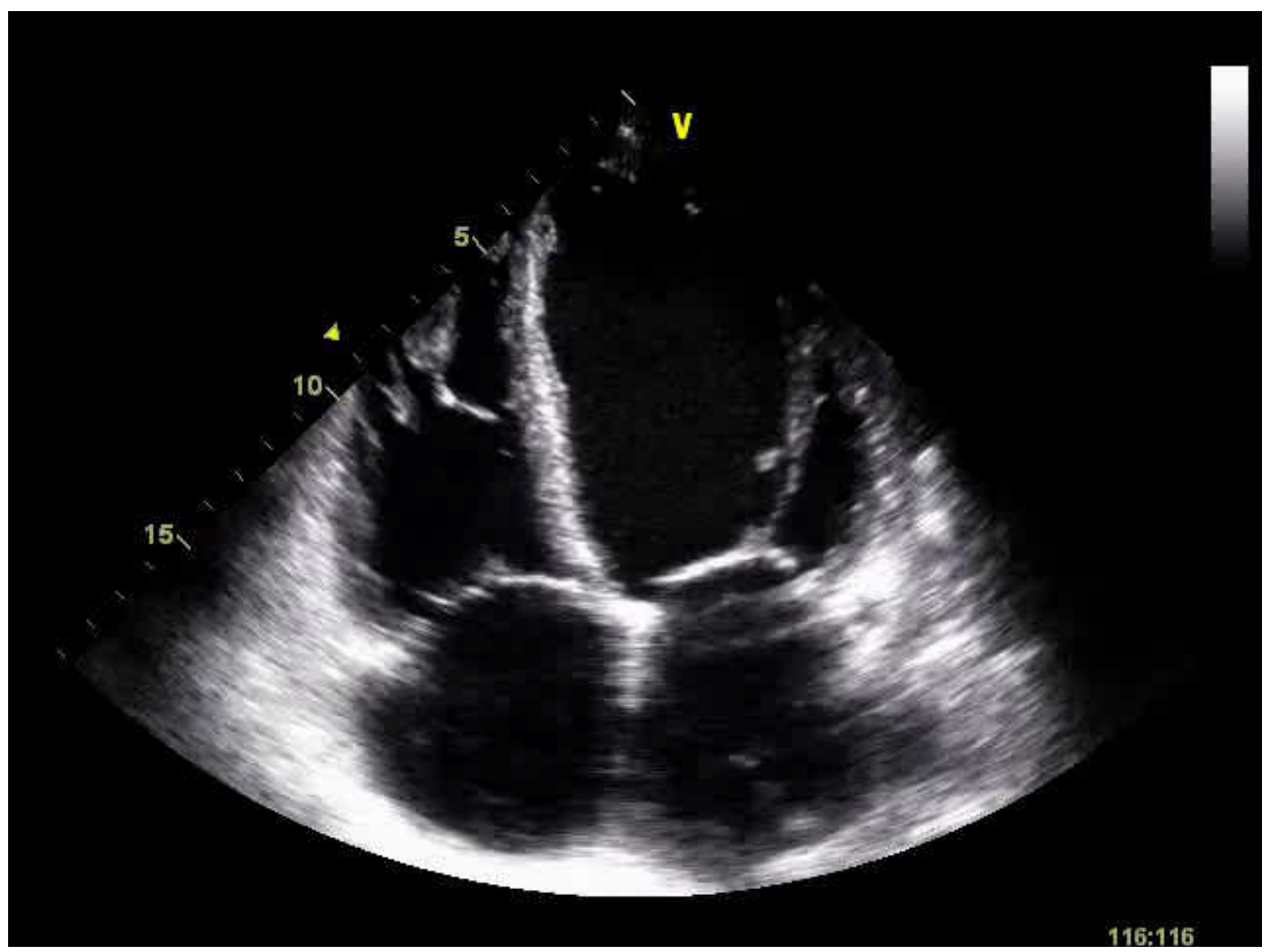

Video 1 - Apical four chamber video, showing severe left ventricular dysfunction (ejection fraction estimated in $10 \%$ ) as well as severely depressed right ventricular function (tricuspid annular plane systolic excursion of $10 \mathrm{~mm}$ )

Despite the initial instability requiring inotropic support, iv diuretics and antibiotics (amoxicillin and clavulanic acid), there was progressive positive evolution. Oral anticoagulation was initiated and the patient was eventually discharged, clinically stable and asymptomatic at rest, under carvedilol $12.5 \mathrm{mg}$ twice per day, spironolactone $12.5 \mathrm{mg}$ per day, lisinopril $2.5 \mathrm{mg}$ per day and furosemide $40 \mathrm{mg}$ twice per day. Even after social support warranting free medication and after explained the potential risks, the patient strictly refused to maintain anticoagulation at home and despite forwarded to a heart failure clinic, he was lost to follow up.

\section{DISCUSSION}

The presence of congestive heart failure, chamber dilatation and low cardiac output promote the thrombogenic process. ${ }^{4}$ Thus, the incidence of mural thrombi is high in patients with dilated cardiomyopathy. In one autopsy series, thrombus was found in $53 \%$ of patients who died from dilated cardiomyopathy; $45 \%$ of thrombi were in the left ventricle, $25 \%$ in the right ventricle, $20 \%$ in the right atrium, and $8 \%$ in the left atrium. ${ }^{1}$

Right heart thrombi are diagnosed and characterized by echocardiography. In 1989, the European Working Group on Echocardiography identified three patterns of right heart 


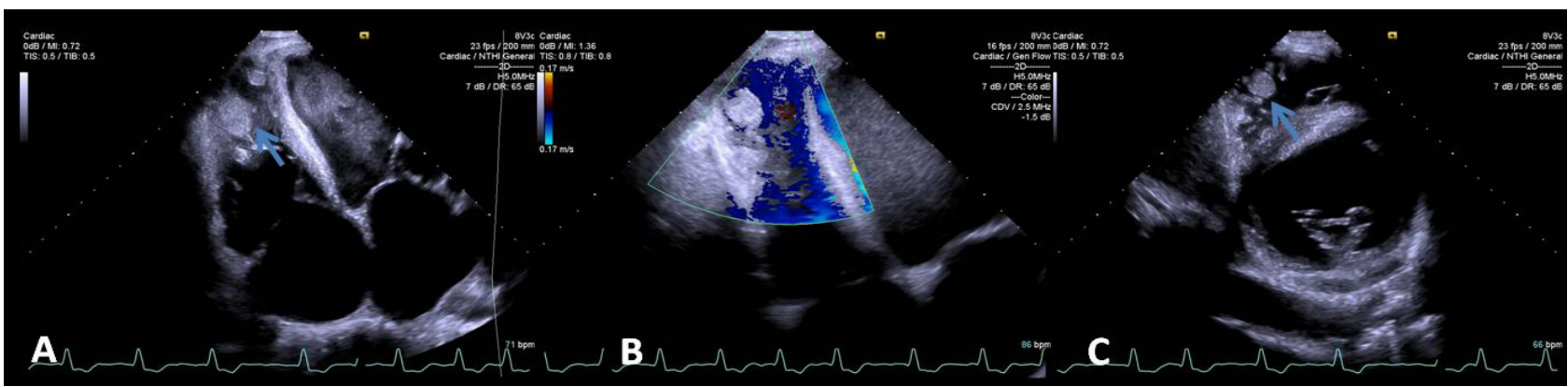

Figure 2 - High frequency probe acquisition allowing for a better characterization of the thrombus (arrows) which was found to be large, non mobile and multilobed. A and B - modified apical four chamber view, without and with color Doppler, respectively; C - parasternal short axis view

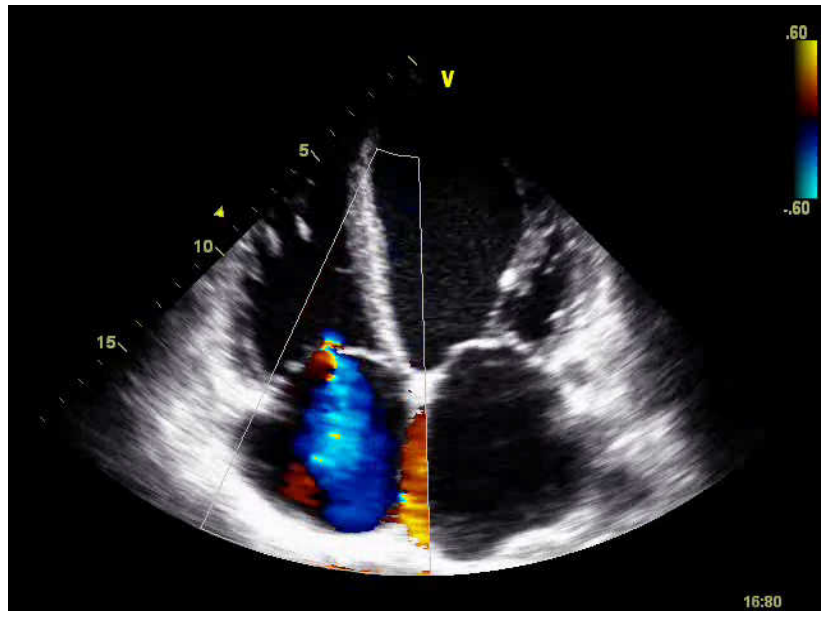

Video 2 - Apical four chamber video, documenting severe functional tricuspid regurgitation

thrombi. ${ }^{5}$ Type A thrombi are morphologically serpiginous, highly mobile masses moving within the right atrium or ventricle, which often prolapse into the tricuspid or pulmonic valve during the cardiac cycle. ${ }^{5} \mathrm{~A}$ point of attachment often is unseen or is visualized as a thin stalk. ${ }^{5}$ They are associated with deep vein thrombosis and pulmonary embolism: it is hypothesized that these clots embolize from large veins and are captured in-transit within the right heart in their path to pulmonary tree. Predisposing factors for these thromboemboli include prominent Eustachian valves, tricuspid regurgitation, low cardiac output and pulmonary hypertension.

Type B thrombi are non mobile, mural and believed to form in situ, in association with underlying cardiac abnormalities. ${ }^{5}$ Echocardiographically, these mural thrombi present less motion during the cardiac cycle, a broadbased attachment to the heart wall, and occasional focal calcification. ${ }^{5}$

Type $C$ thrombi are rare, share a similar appearance to a myxoma and are highly mobile.

Right heart thrombi are most often seen in the setting of an acute pulmonary embolism: there is imaging evidence of type A thrombosis in up to $18 \%$ of cases, especially in hemodinamically compromised patients and this finding is

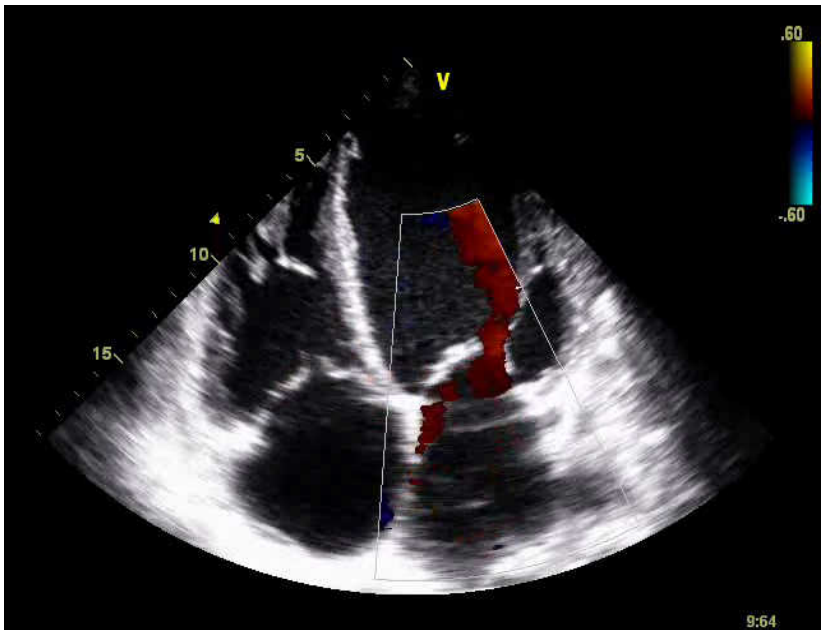

Video 3 - Apical four chamber video, documenting severe functional mitral regurgitation, with Coanda effect

associated with a worse prognosis. On the other hand, type $B$ thrombi are frequently an incidental finding.

Referring to the therapeutic options, some authors have previously cautioned against the use of thrombolytic agents in type B thrombi: thrombolytic agents may dissolve the adherent stalk and actually promote distal embolism of these organized thrombi. Conversely, a prospective case series reported favorable in-hospital survival for patients with type A thrombi treated with thrombolytics. Despite this, the optimal management of right heart thromboemboli remains unclear because there are no prospective randomized trials comparing anticoagulation therapy, thrombolytic therapy, and surgical removal.

The overall mortality for type A thrombi is $28 \%$ to $44 \%$. Although the prevalence of type $B$ thrombi is unknown, they portend better outcomes than type $A$ thrombi.

We presented a case of a patient with alcoholic dilated cardiomyopathy, in whom severe biventricular dysfunction and stasis promoted the formation of a large right ventricular thrombus. This thrombus, incidentally detected, met the criteria for being classified as a type B thrombus. Given the clinical stability and the eventual risk for thrombus fragmentation and embolization, the patient was not considered a candidate for thrombolysis, or for 
surgery. This patient was proposed to an anti-coagulation regimen, which he refused. Therapeutic non compliance is a very relevant issue in medical practice and often it is multifactorial. In this particular case, the patient initially alleged that he had no economical capacity to maintain the prescribed medication. However, even after social services intervention, ensuring medication obtainment at no cost, the patient maintained his refusal. Eventually he confessed that he didn't want to take the medication because he was afraid of possible interactions with the alcohol ingestion which he intended to keep. He maintained this position even after explained the inherent risks and he even missed the psychiatry appointment to which he was referred. In this kind of cases of medication noncompliance secondary to psychological reasons such as an addition, family support is of utmost relevance. Also here, the options were exhausted: the patient was found to have no near relatives who could eventually help in this situation.

\section{REFERENCES}

1. Waller BF, Rohr TM, McLaughlin T, Grider L, Taliercio CP, Fetters J. Intracardiac thrombi: frequency, location, etiology, and complications: a morphologic review - part I. Clin Cardiol. 1995;18:477-9.

2. Maagh P, Butz T, Ziegler A, Meissner A, Prull MW, Trappe HJ. The first three-dimensional visualization of a thrombus in transit trapped between the leads of a permanent dual-chamber pacemaker: a case report. J Med Case Rep. 2010;4:359.

3. Dogan SM, Birdane A, Korkmaz C, Ata N, Timuralp B. Right ventricular

\section{CONCLUSION}

Right ventricular thrombosis constitutes a rare yet potentially fatal situation, whose optimal management remains controversial. The described case illustrates the crucial role of transthoracic echocardiography as the election diagnostic tool in this setting, as it allows for the thrombus detection and characterization, with the inherent therapeutic strategy implications. Additionally, it represents a situation in which therapeutic non compliance prevails despite all medical efforts.

\section{CONFLICTS OF INTEREST}

The authors declare that they do not have any conflicts of interest as far as this article is concerned.

\section{FUNDING SOURCES}

There are no relationships with industry. No financial external sources contributed to the elaboration of this article.

thrombus with Behçet's syndrome: successful treatment with warfarin and immunosuppressive agents. Tex Heart Inst J. 2007;34:360-2.

4. Torbicki A, Galié N, Covezzoli A, Rossi E, De Rosa M, Goldhaber $\mathrm{SZ}$; et al. Right heart thrombi in pulmonary embolism: results from the international cooperative pulmonary embolism registry. J Am Coll Cardiol. 2003:41:2245-5.

5. Kronik G. The European cooperative study on the clinical significance of right heart thrombi. Eur Heart J. 1989;10:1046-59. 
Carla SOUSA, Pedro ALMEIDA, Alexandra GONÇALVES, João RODRIGUES, Inês RANGEL, Filipe MACEDO, M. Júlia MACIEL

\section{Large Right Ventricular Thrombus \\ Acta Med Port 2014:27:390-393}

Publicado pela Acta Médica Portuguesa, a Revista Científica da Ordem dos Médicos

Av. Almirante Gago Coutinho, 151

1749-084 Lisboa, Portugal.

Tel: +351218428215

E-mail: submissao@actamedicaportuguesa.com

www.actamedicaportuguesa.com

ISSN:0870-399X | e-ISSN: 1646-0758

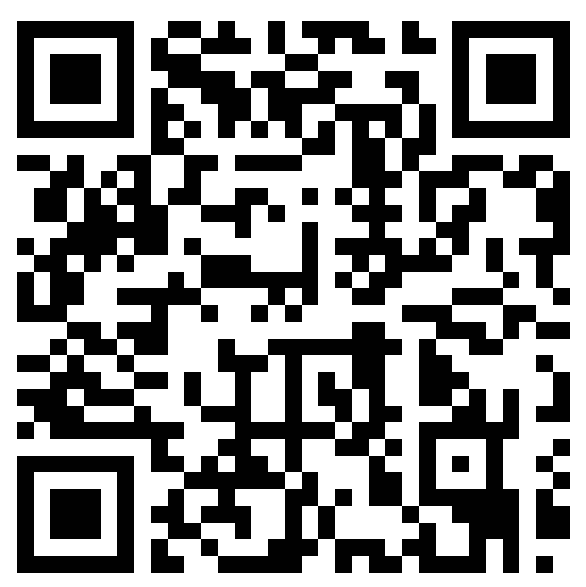

ACTA MÉDICA

PORTUGUESA 